\title{
Physiological limits to growth and the related effects on meat quality
}

\author{
E.C. Webb *, N.H. Casey \\ Department of Animal and Wildlife Sciences, University of Pretoria, Pretoria 0002, South Africa
}

\section{A R T I C L E I N F O}

Available online $\mathrm{xxxx}$

\section{Keywords:}

Physiological limits

Growth

Meat quality

Stress

PSE

DFD

Double-muscling

Callipage

Ascites

Metabolic defects

\begin{abstract}
A B S T R A C T
Commercialisation of animal agriculture changed the phenotype and production characteristics of livestock. The sigmoidal growth curve and sequence of physiological events remained virtually unchanged, but the rate and extent of these processes increased remarkably. Physiological limits to growth are apparent in species selected for accelerated growth and production, like stress sensitivity, PSE and DFD syndromes in livestock, doublemuscled cattle, the callipage gene in sheep, ascites and associated metabolic defects in broilers, leg problems in layers, abortions in Angora goats, wet carcass syndrome in sheep, and other tissue defects as well as reproductive failure due to interactions between the growth hormone cascade, gonadotrophic axis and endocrine factors that regulate metabolism like thyroxin and leptin.

Although, the physiology of animals is generally quite forgiving, there are warning lights on the horizon. The challenge in livestock production should shift towards synchronising the best genotypes in a specific environment with the most appropriate and environmentally acceptable technologies available to produce consistently high quality meat. Manipulation of the quality of animal products through feeding, breeding and physiology will become increasingly important, provided that these technologies are practical, economical and do not detract from the intrinsic and extrinsic attributes of animal products, or any other aspect relating to environmentally acceptable or ethical livestock production.
\end{abstract}

(c) 2010 Elsevier B.V. All rights reserved.

\section{Introduction}

Domestication of livestock, poultry and pigs occurred during the Neolithic period (5000 and 11,000 years ago) or "Neolithic revolution" in different regions around the world and forever changed the history and fate of humankind (Childe, 1936; Gupta, 2004). The domestication of livestock is characterised by five major shifts, each of which was brought about mainly by the increasing demand for a sustainable supply of good quality protein for human consumption, but the process was also accelerated by a number of biological, environmental, economical and ethical limitations. The current high demand for products from animal origin and

\footnotetext{
* Corresponding author. Tel.: +27 12 4204018; fax: +27 124203290 .

E-mail address: Edward.webb@up.ac.za (E.C. Webb).
}

the associated dynamics of animal breeding in developing countries due to the increasing population, urbanisation and disposable incomes are pertinently described as the "livestock revolution" (Steinfeld, 2004).

It is predicted that the livestock revolution will have major consequences on animal and human health and probably change the face of modern agriculture in decades to come. The contribution of developing countries to world livestock production and consumption is expected to increase considerably, while the opposite is expected in most developed countries (Steinfeld, 2004). Higher levels of animal production can be achieved either through an increase in the number of livestock or an increase in productivity. The latter usually involves more intensive feeding, fattening, shorter production cycles and higher product yields.

The increase in livestock production and consumption in developing countries will probably be achieved through more intensive animal production systems, selecting animals based 
on production efficiency, making use of modern feeding and breeding technologies and increasing use of cereal-based animal feeds. Developed countries exhibited similar trends since the 1970s, but consistent selection pressure on production efficiency has yielded mixed results. Increasing demands for products from animal origin have significant consequences on natural recourses like the availability and quality of water, soil, pastures as well as concomitant effects on biodiversity and environmental pollution. Intensive livestock production results in an increased recycling of the minerals $\mathrm{N}, \mathrm{P}$ and $\mathrm{K}$ and heavy metals $\mathrm{Cu}, \mathrm{Zn}$ and As via faeces back into the environment (Yao and Dang, 2006). These adverse effects of intensive feeding are becoming a worldwide dilemma.

There is also evidence that some of the modern breeds of livestock have reached their physiological limits resulting in more difficulties in terms of adaptation, reproduction and the quality of animal products. The aim of this overview is to examine the consequences of selection for growth and production efficiency on meat quality.

\section{Dynamics of livestock domestication}

The domestication of animals was driven primarily by peoples' need to secure food for times when hunting was poor. Consequently people were "freed" from the labour of collecting food into doing other work resulting in the establishment of sedentary communities across the world (Webb, 2006). This represents the first important shift in the domestication of livestock, namely that from hunter-gatherer to agriculturalists.

Domestication and the increasing dependence on animal agriculture eventually prompted the "then developing" livestock industry to focus on increasing livestock numbers, followed by maximum yield. The latter endeavour was achieved through improved breeding, feeding, caring, management and health of domestic animals. Developing countries are currently going through such a phase, characterised by a greater increase in productivity of livestock compared to the increase in livestock numbers (Steinfeld, 2004).

In developed countries an increase in livestock numbers is severely limited by the availability of agricultural land, so increasing demands for animal products can only be met by improvements in the productivity of livestock. The livestock sector was very successful in improving productivity through improved breeding, nutrition and manipulating the underlying principles of growth notably hypertrophy, hyperplasia and differentiation (Webb, 2006; Harris, 1970). This represents the second important shift namely that from merely providing food, to providing a consistently high amount of food for financial gain.

These quantitative production goals for many years dominated the livestock industry and were propagated at all major agricultural fairs and shows until the early 1950s. However, it soon became apparent that injudicious animal breeding and selection is a risky business that requires a more scientifically responsible approach. Again the emphasis in livestock breeding shifted - this time towards more accurate measurement and quantification of a variety of internal and external effects and their interactions on genetic and phenotypic variation. This occurred almost simultaneously along with the focus on efficiency of livestock production, limited resources and the economy of feeding and fattening livestock in semi-extensive and intensive production systems. Animals were selected for functional efficiency by means of visual appraisal and other objective measurements of efficiency like average daily gain and feed conversion efficiency. This probably represents the third shift notably from maximum yield to efficiency. Although the emphasis on production efficiency remained an important goal in livestock production, Harris (1970) concluded that there is little benefit to producers other than increased production, while the products may be more affordable to consumers. The emphasis on efficiency in livestock production systems also focussed more attention on intensive fattening and finishing systems and the effects of animal handling and stress on animal welfare and product quality. It is now widely accepted that proper animal handling and reduced stress improve the productivity, welfare and quality of animal products (Grandin, 1998).

Significant progress has been made in terms of the quantification of growth and growth limits, the factors that affect growth and development, nutrition and nutrient partitioning, and growth manipulation through nutritional interventions and endocrine and genetic manipulation. The recent advent of molecular techniques, identification of quantitative trait loci (QTL), candidate genes and single nucleotide polymorphism (SNP) markers have also added a new dimension to our understanding of these processes (Andersson and Georges, 2004; Green et al., 2007; Blasco, 2008). These technologies represent the epitome of modern animal production.

However, recently the concept of product "quality", was adopted which exposed the multi-dimensional nature of consumers' perceptions regarding meat quality. Consumers are becoming increasingly more concerned about what animals are fed and how these feed additives affect the wholesomeness and safety of animal products (Sapkota et al., 2007). There is an increasing perception that animal feeding practices result in the presence of antibiotic-resistant bacteria, prions, arsenicals and dioxins in products from animal origin. This situation is deteriorating despite the implementation of feed rules, the ban on the use of antibiotic substances and selected growth promoting substances in feedstuffs and more evidence (Eckel et al., 2008) that substances like heavy metals also accrue from atmospheric deposition.

The challenge in livestock production is now shifting towards synchronising the best genotypes in a specific environment with the most appropriate and environmentally acceptable technologies available (such as functional genomics, proteonomics and metabolomics) to produce consistently high quality meat in accordance with consumer needs.

\section{Use of transgenic livestock and genomics to improve growth and production}

Although only a few transgenic animals are commercially available, progress has been made in terms of improving livestock production through transgenic technologies, which remain one of the promising alternatives on the horizon. The first techniques to genetically modify livestock were developed during the 1980s. The use of pronuclear microinjection 
of DNA into fertilized zygotes, to produce transgenic livestock is expensive (Blasco, 2008) and suffers from the compounded inefficiencies of low embryo survival (Maga et al., 2003). There has been excitement about the transfer of the recombinant somatotropin (ST) gene, but research to date suggests that unless the expression of the gene is controlled, the health status of transgenic animals is adversely affected (Bonneau and Laarveld, 1999). In addition, it appears that transgenic animals frequently suffer from reproductive problems (Blasco, 2008).

Physiological control mechanisms at the cellular level seem to prevent artificial manipulation of DNA and this requires further research. Fortunately the use of recombinant proteins that bind DNA (RecA protein-coated DNA) holds more promise in terms of the production of transgenic livestock via pronuclear microinjection techniques. In an overview of the expectations of transgenesis over the past 25 years, Blasco (2008) concluded that the benefits produced by this technology does not justify the risks, which include difficulties in identifying superior animals, the need to test large numbers of animals and the serious loss of genetic material after successful cloning. Other alternatives are also available like the use of embryonic stem cells and nuclear transfer, but more research is required in this regard.

Developments in the field of genomic research in livestock were boosted by the Human Genome project and resulted in the sequencing of the Bos taurus (bovine) and Gallus domesticus (chicken) genomes (Green et al., 2007) and the porcine genome project is currently in progress. These technologies will improve our understanding of the genetic variation of economically important production traits, while at the same time reducing the occurrence of physiological defects and metabolic syndromes in livestock. More research is required to understand the underlying physiological processes, genomic-environmental interaction which (functional genomics) in order to identify desirable traits and eliminate undesirable traits.

Aspects of livestock production that stand to benefit most from this process include meat quality and product yield in beef cattle, milk production and resistance to mastitis in dairy cattle, litter size and uterine capacity in pigs, carcass composition and yields in sheep, and efficiency of growth, product quality and coccidia resistance in poultry (Green et al., 2007; Blasco, 2008). The environmental risks associated with transgenic livestock are regarded to be considerably less compared to genetically modified plants (Sang, 2003). Nevertheless, it appears that the benefits produced by transgenic livestock do not justify the risk yet (Blasco, 2008).

\section{Use of genomics to improve meat quality in livestock}

Meat quality and the physiological processes that affect meat quality are controlled by a delicate interaction between multigenes (additive gene action) and the environment. Gao et al. (2007) described the use of genome scans and candidate genes to identify loci associated with a variety of meat quality traits in different species of livestock. Different approaches are possible namely (1) the use of candidate genes and (2) genome scans for QTL's (QTL mapping). A high correlation between a candidate gene and a physiological characteristic can represent a very effective way to detect loci or traits with small effects. However, the physiological process is often poorly understood or a number of candidate genes are linked to a trait.

Genome scans are used to identify a trait locus with a major effect so QTL mapping represents a popular way to employ genomics in livestock (Gao et al., 2007). For example, the animal quantitative trail loci database contains 1675 QTL's which represent 281 traits in the pig, 846 traits in cattle, and 657 traits in the chicken. Polymorphic genetic loci are identified, followed by marker assisted selection (MAS) while gene assisted selection (GAS) may become a more viable option in future.

Permanent genetic improvement in performance and product quality can be achieved by employing these techniques, but Gao et al. (2007) stresses that these techniques should be used as an additional tool along with quantitative genetic techniques. These methodologies have great potential in terms of improving livestock production provided that the underlying physiological processes are well understood and the animals' physiology is not pushed over acceptable homeostatic threshold values.

\section{Improvements in growth and efficiency of livestock}

The commercialisation of animal agriculture resulted in a significant change in terms of both the phenotype and production characteristics of modern breeds of livestock. Although the basic form of the sigmoidal growth curve as well as the sequence of physiological events remained virtually unchanged (Webb and Casey, 2005), the rate and extent of these processes increased remarkably. Scientific methodologies and techniques developed and employed in animal studies have yielded remarkable results in all species of livestock notably beef and dairy cattle, poultry, sheep and aquaculture (Green et al., 2007).

The fattening period of feedlot cattle was reduced to approximately 100 days, with growth rates of up to $2 \mathrm{~kg}$ per day and feed efficiencies varying between 5 and $6 \mathrm{~kg}$ of feed for $1 \mathrm{~kg}$ of live weight gain (Webb, 2006). Milk yields of dairy cattle of up to $90 \mathrm{~kg}$ per day have been recorded, while consistent yields of up to $27,000 \mathrm{~kg}$ over a 365 day lactation period ( $75 \mathrm{~kg} /$ day) are achievable with modern breeding and nutritional inputs. The hatching weight of chicks is ca. $44 \mathrm{~g}$ and only a few years ago broilers were market ready after a 16 week feeding period, but due to selection pressure on growth and appropriate nutritional inputs, broilers are now marketed at $2.4 \mathrm{~kg}$ after an intensive feeding period of only 42 days. During this period, broilers can easily achieve a feed conversion ratio of about $1.8 \mathrm{~kg}$ of feed for $1 \mathrm{~kg}$ live weight gain. Similar changes occurred in commercial pig production systems by increasing the selection pressure on lean carcass yield, resulting in a significant decrease in back fat thickness $(<12 \mathrm{~cm})$ and carcass fat content.

Increasing selection pressure on growth and feed efficiency resulted in the marginalisation of some of the smaller and less productive breeds of livestock, typically those on the far left of the normal distribution curve (Webb, 2006). The physiology of animals is generally quite forgiving but there are warning lights on the horizon. It appears that we have reached the physiological limits to growth in a number of species. Examples include double- 
muscled cattle (doppellender gene in Belgian Blue cattle and other breeds), the callipage gene in sheep (heavy muscled sheep breeds), ascites and associated metabolic defects in broilers selected for accelerated growth rates, leg problems in high producing layers, stress sensitivity, PSE and DFD syndromes in pigs selected for accelerated protein accretion, abortions in Angora goats selected for mohair production, wet carcass syndrome in sheep, as well as a variety of tissue defects and reproductive failure in herds selected for high yields through interactions between the growth hormone cascade, the gonadotrophic axis and other endocrine factors that regulate metabolism like thyroxin and leptin.

\section{Consequences of selecting livestock for growth and efficiency}

Progress has been made in terms of improving growth and efficiency of feed utilisation in livestock. Growth rate is a good indicator of efficiency because a higher growth rate is associated with a lower maintenance requirement and thus a saving in feed costs (Whittemore, 1993). Improvements in feed efficiency are mostly due to increased growth rates and selection for lean growth. However, there is growing consensus that little opportunity exists for further improvements in efficiency of feed utilisation for growth and lactation, while improvements in the efficiency of maintenance functions appear to be more attractive (Pitchford, 2004). Other researchers (Green et al., 2007) are also concerned about the negative side effects of enhancements in production efficiency on animal well-being, longevity, increased animal waste, lower reproduction efficiency and increased susceptibility to stress and metabolic and infectious diseases.

The current dilemma is that selection for improved maintenance efficiency appears to compromise the normal physiology of livestock. For example, selection for improved net feed efficiency in pigs (Webb and Mamabolo, 2004) and cattle (Pitchford, 2004) has been associated with a decrease in carcass fatness. Webb et al. (2006) also reported a decrease in gonadal development in pigs selected for high lean growth, while Pitchford (2004) observed a decreased reproductive rate in cattle similarly selected. The results of Taylor et al. (2008) also suggest that selection for high growth rates in combination with intensive fattening of young bulls adversely affect the development and functioning of seminiferous tubules and subsequent semen quality. There are concerns about selection for improved net feed efficiency in livestock, but the consequences on stress responses in livestock and the related meat quality defects are also problematic.

\section{Effects of selection for growth and efficiency on meat quality}

The most dramatic effects of selection for growth were demonstrated in studies in transgenic mice carrying the human growth hormone gene (Sang, 2003), which resulted in mice growing significantly larger than their normal counterparts. These studies emphasised the remarkable potential of genetic engineering in livestock, but the possibilities are certainly not unlimited. In a study with transgenic pigs for growth hormone, Pursel et al. (1989) clearly showed that manipulation of growth and efficiency may have adverse anatomical and physiological effects. These transgenic "Beltsville pigs" suffered from severe leg problems and arthritis due to an uncontrolled expression of the modified growth hormone gene.

Adverse effects were also observed in cattle and sheep after manipulation of the myostatin gene and more specifically the down-regulation of the expression of the myostatin gene. This resulted in excessive muscling and lean yield, while adverse effects include leg problems, macroglossia (enlarged tongue), weak bones, erythrocyte fragility, altered endocrine regulation, higher susceptibility to heat stress and lower reproductive capacity (Swatland, 1984). In this regard it is also important to note that different breeds of cattle may contain different alleles of the myostatin gene, which means that the consequent effects on muscular hypertrophy and meat quality differ in different genotypes (Short et al., 2002).

The consequences of selection for accelerated growth and efficiency on meat quality are often exhibited when animals are exposed to environmentally induced stress or poor housing, handling and transportation conditions. Livestock stressed before slaughter may yield carcasses that exhibit undesirable meat quality. The most common defects include "pale soft exudate" meat (PSE) and "dark firm dry" meat (DFD). The PSE condition is quite common in pigs and chickens, while the DFD condition is more common in cattle. These stress-induced conditions are direct consequences of a disruption in normal physiological processes pre- and postmortem, which are often more pronounced in high yielding breeds of livestock. Physiological changes that occur subsequent to stress usually involve a marked increase in heart rate, blood pressure, body temperature and respiration rate, subsequent to the release of the cathecolamines, epinephrine and norepinephrine. Energy metabolism is altered and this involves rapid metabolism of phosphocreatin $(\mathrm{PCr})$, glycogen and glucose which significantly affect the conversion of muscle to meat. Under normal conditions the physiological goal is to maintain ATP concentrations in muscle tissue constant in order to maintain homeostasis. This is usually achieved by aerobic metabolism of $\mathrm{PCr}$, glycogen and glucose, but if muscle contraction proceeds rapidly and energy demand increases above the available reserves, oxygen becomes limiting resulting in anaerobic glycolysis, which produces lactate, $\mathrm{H}^{+}$and heat (Scheffler and Gerrard, 2007). Lactate accumulates in muscle tissue because there is no mechanism in post-mortem muscle to eliminate such waste products.

The type of stressor and duration affect the rate and extent of glucose and glycogen metabolism and depletion. For example, glucose is generally oxidised to energy, carbon dioxide and water, but in the absence of oxygen, glucose is converted less effectively to energy, water and an excessive amount of lactic acid. The conversion of glucose to lactic acid influences the rate of $\mathrm{pH}$ decline in muscle and other tissues, and this significantly affects meat quality. An excessively high conversion of glucose to lactic acid (usually due to severe short term stress/acute stress) will cause a too rapid decrease in muscle $\mathrm{pH}$ ( $\mathrm{pH}$ decreases to below 6.0 within $1 \mathrm{~h}$ post-mortem), release of proteolytic enzymes and disruption in cellular integrity, while the abnormally low $\mathrm{pH}$ causes denaturation (Scheffler and 
Gerrard, 2007) of sarcoplasmic and myofibrillar proteins (typical PSE condition).

Research also indicates that pigs selected for high rates of growth and which are associated with PSE, exhibit aberrant calcium metabolism (Barbut et al., 2008). These researchers reported that extreme cases of the PSE condition in pigs, showed a point mutation in the 615 amino acid (Arg615Cys) which causes abnormally high release of $\mathrm{Ca}^{2+}$ from sarcoplasmic release channels in post-mortem muscle. This results in abnormally high concentrations of sarcoplasmic $\mathrm{Ca}^{2+}$ which increases muscle metabolism and elevates lactate production above normal concentrations. Although meat defects and problems with poor water holding capacity are still reported by industry, it seems that progress can be made by identifying and eliminating pigs that are severely affected by PSE (Barbut et al., 2008). These researchers concluded that a "status quo" has been reached between production of pork quantity and quality, and that the focus in the pork industry is shifting towards "best cost production of consumer quality products".

\subsection{Muscle defects in pigs due to selection for accelerated growth}

The PSE condition is associated with the porcine stress syndrome (PSS) which is linked to a single autosomal recessive gene (Barbut et al., 2008) and was mapped to chromosome 6 (Gao et al., 2007) and causes malignant hyperthermia. It is estimated that the PSE syndrome affects about $15 \%$ of the pigs produced in the USA and cost the pork industry approximately $\$ 100$ million per annum (Scheffler and Gerrard, 2007). PSS was initially detected in pigs by exposure to halothane gas, but it was established (Fujii et al., 1991) that the condition is due to a recessive mutation of the RYR1 gene, which refers to the ryanodine receptor that regulates the release of $\mathrm{Ca}^{2+}$ in skeletal muscle. Continued selection pressure on carcass yield and low carcass fat content resulted in a larger number of homozygous and heterozygous halothane stress-sensitive pigs that exhibit the PSE condition.

Rosenvold and Andersen (2003) identified a single gene that influence meat quality and carcass yield in pigs namely the Napole technological yield condition ( $\mathrm{RN}, \mathrm{RN}^{-}$and $\mathrm{RN}^{+}$), mapped to chromosome 15, which occurs in the Hampshire pig breed and their crosses. This condition has been linked to a mutation of a gene (PRKAG3 gene), again due to selection pressure on growth and lean yield (Milan et al., 2000), which caused a change in the regulatory subunit of adenosine monophosphate kinase and consequently an accumulation of excess glycogen in skeletal muscle of $\mathrm{RN}^{-}$pigs. Similarly, selection for growth and lean content resulted in a mutation of the insulin like growth factor 2 (IGF2), which was traced to chromosome 2 (Van Laere et al., 2003) and had major effects on muscle growth and fat accretion in pigs. This increase in muscle growth has been positively linked to postnatal muscle hypertrophy due to increased muscle fibre diameter and proliferation in pigs carrying the IGF2 gene (Van den Maagdenberg et al., 2008). However, the IGF2 genotype or RYR1 genotype did not affect the muscle fibre type composition or metabolic enzyme activities.

Rapid depletion of muscle glucose and glycogen (usually due to exhaustion or longer term exposure to stress/chronic stress) result in very low conversion of glucose to lactic acid and minor $\mathrm{pH}$ decrease ( $\mathrm{pH}$ remains above 6.0 for up to $24 \mathrm{~h}$ post-mortem; typical DFD syndrome). In the latter case, the meat appears dark, firm and dry and it is more prone to bacterial contamination and meat spoilage. DFD has been documented in pigs exposed to chronic or long term stress where energy reserves are depleted and lactic acid formation is inadequate for the normal conversion of muscle to meat. Ante mortem stress and environmental factors like temperature and humidity appear to predispose pigs to this condition, while the RYR1 genotype had no effect on the incidence of DFD (Guàrdia et al., 2005).

\subsection{Muscle defects in poultry due to selection for accelerated growth}

Selection for growth, feed conversion efficiency and white meat yield changed the physiology of chickens significantly (Pavlidis et al., 2007). Chickens selected in this way are generally more prone to PSE, although the mechanism involved in triggering the PSE gene in poultry is not fully understood (Cavitt et al., 2004). These researchers could not identify birds prone to PSE regardless if they were sensitive to halothane or succinylcholine. In another experiment with broilers, higher breast muscle weights were recorded in chickens selected for growth and this correlated positively with fibre size (Le Bihan-Duval et al., 2008), but correlated negatively with glycolytic potential (GP - the level of glycogen stored in muscle) and resulted in relatively high muscle pH. Swatland (2008) clearly demonstrated the effects of high and low muscle $\mathrm{pH}$ post-mortem in chickens on the development of dark or pale muscle colour respectively. He showed that differences in light scattering between PSE and DFD chicken meat are due to myofibrillar refraction of scattered light, which corresponds with that described in pork and beef.

There is reportedly little conflict between selection for meat quantity and quality in chickens (Le Bihan-Duval et al., 2008), but it is admitted that genetic markers or quantitative trait loci (QTL's) will have to be employed to prevent a deterioration in chicken meat quality. A gene was identified that affects abdominal fat accumulation in chickens which is referred to as extracted extracellular fatty acid gene (EX-FABP). Other QTL or QTN markers will have to be identified to manage the PSE and DFD conditions in chickens.

Turkeys selected for fast growth also exhibited a "pale meat problem" (McCurdy et al., 1996), which was later linked to $\mathrm{Ca}^{2+}$ channel ryanodine binding (Wang et al., 1999) and corresponds with the similar problem described in pigs, although post-mortem glycolysis is about three times faster in poultry compared to pigs. Wang et al. (1999) found that turkeys selected for fast growth showed a higher affinity for $\mathrm{Ca}^{2+}$ channel ryanodine binding compared to their unimproved counterparts. Since there is no reliable marker to select against PSE in turkeys, management practices like reduced stress before slaughter, improved loading of birds, lower stress stunning techniques and chilling rates are employed to better manage PSE sensitive birds (Barbut et al., 2008).

A bluish discoloration of poultry skin (poultry cyanosis) has also been noted and this condition is apparently similar to the DFD condition. Stress and exposure to cold conditions 
predispose chickens to this condition, and the condition is more common in chickens selected for accelerated growth and efficiency.

Broiler chickens intensely selected for rapid growth and feed efficiency coupled to environmental stressors like high temperatures also suffer a condition known as ascites (Luger et al., 2003), which is characterised by hypoxemia, increased pressure on the cardio-pulmonary system, central venous congestion, fluid exudation in peritoneal cavity and death. It was shown experimentally that ascites sensitive chickens exhibit an increase in hematocrit, blood cell counts, packed cell volumes and blood volumes, while plasma volumes remained unchained. Erythropoiesis and red blood cell formation were associated with increasing corticosterone concentrations in fast growing chickens. Although hematocrit values were elevated, blood oxygen saturation levels were reduced (Luger et al., 2003).

In a more recent study (Hassanzadeh et al., 2008) it was shown that the ascites condition in broilers is due to right ventricular hypertrophy in birds selected for rapid growth and that exposure of eggs during incubation to high altitudes (chronic hypoxia) may reduce the incidence of ascites by improving the gas exchange area of birds post hatch. Subsequently, it was indicated that selection based on $\mathrm{pCO}_{2}$ tension in venous blood of birds 11 days of age may provide a means of reducing the incidence of ascites in broilers (Scheele et al., 2003). It was also found that direct selection for resistance to ascites is effective in broilers, but resulted in a decrease in body weight in both ascites resistant and susceptible lines (Pavlidis et al., 2007). However, ascites is invariably linked to production traits in poultry and it appears that the limit between quantity and quality has been reached.

\subsection{Muscle defects in cattle due to selection for accelerated growth}

Dark, firm and dry (DFD) beef occurs in cattle as a result of chronic exposure to stressful conditions or strenuous muscular activity before slaughter (Viljoen et al., 2002). Chronic exposure to stress cause a depletion of glycogen reserves in muscle and very little post-mortem anaerobic glycolysis and lactic acid formation. The consequence is that muscle $\mathrm{pH}$ remains relatively high (ultimate $\mathrm{pH}_{\mathrm{u}}>5.8$ ) and meat from affected animals spoils more rapidly than normal ultimate $\mathrm{pH}$ meat (Newton and Gill, 1977). Consumer studies confirm that raw DFD beef steaks are appreciably less acceptable compared to normal beef steaks, but no significant differences were observed in the sensory attributes of fried normal and DFD beef steaks (Viljoen et al., 2002).

The DFD condition in cattle is also subject to environmental influences like cold, hot, wet and humid or fluctuations between cold and hot conditions. Seasonal differences in the incidence of DFD beef have been noted and although this can be managed, cattle selected for growth appear to be more susceptible to DFD. In an extensive study by Perry and Thompson (2005) in 7000 beef cattle from temperate and tropical breeds, a positive relationship was observed between growth and palatability of strip loins. Increased growth during backgrounding improved the palatability of strip loins from different breed types fed different diets. These findings are positive from a consumer perspective, but complicate the management of DFD in cattle.
Some studies (Fishell et al., 1987) suggest that faster growing cattle had more tender meat compared to slower growing cattle, while others found no differences in meat tenderness (Calkins et al., 2000). Perry and Thompson (2005) argue that fast growing cattle reach market weight at an earlier age and are thus younger at slaughter, yielding more tender meat, compared to slower growing counterparts. Overall, it was concluded that the relationship between growth rate and eating quality independent of age, was evident only within a group basis, while relative differences in growth rate between groups of cattle were not related to beef quality due to environmental constraints. In other words, management efforts aimed at improving the growth rates of cattle resulted in small improvements in eating quality of beef.

A more pronounced example of selection for growth in cattle is the double-muscled condition in certain beef cattle breeds like the Belgian blue, Piedmontese and occasionally in a number of other improved beef breeds. These breeds are characterised by significant improvements in carcass dressing percentage, lean meat yield and low fat content resulting in high meat-yielding carcasses (Webb et al., 1998). Unfortunately side effects were also observed in double-muscled cattle with the myostatin gene. Adverse effects in these genotypes are variable because different breeds contain different alleles, so that the extent of muscular hypertrophy and related effects on meat quality differ between genotypes (Short et al., 2002). It was previously mentioned that muscular hypertrophy is often associated with leg problems, macroglossia, weak bones, erythrocyte fragility, altered endocrine regulation, higher susceptibility to heat stress and lower reproductive capacity. Double-muscled animals also yield beef that tend to be dry, pale and which react differently to cooking compared to beef from normal animals due to the differences in background toughness and calpain and calpastatin enzymes (Webb et al., 1998).

On the other hand, there are a number of alternatives (Sillence, 2004) available to improve production in cattle like the use of modern hormones to manipulate fat and muscle metabolism e.g. leptin, adiponectin and myostatin, the use of polymorphic genes like thyroglobulin to control fat accretion, natural feed additives like betaine, chromium and conjugated linoleic acid to manage fat:lean ratios, and the use of production vaccines or antibodies to neutralise growth limiting factors. However, the current focus should be to identify useful genotypes and select by means of QTL's or QTN's, animals resistant to stress-induced muscular or anatomical defects, or combining genotypes in crossbreeding programmes or by genetic modification in order to improve production in an economically viable way without offending consumers or harming the environment. A significant genetic variation is currently available and the beef industry finds itself in a favourable position in terms of exploiting this vast genetic reservoir, provided that it is done in a scientifically responsible way.

7.4. Muscle defects in sheep and goats due to selection for accelerated growth

Selection for growth and efficiency in Texel sheep resulted in a mutation which caused muscular hypertrophy. According to Gao et al. (2007), this condition is due to a translational 
inhibition of the myostatin gene (GDF8). Similarly the callipage genotype in sheep is linked to chromosome 18 and resulted in significant muscular growth, while adverse effects were reported in terms of meat tenderness. A number of research programmes focussed on the improvement of growth and carcass characteristics in goats, but no major growth and tissue defects have been reported, although goats tend to have a high glycolytic potential and seem to be very sensitive for ante mortem stress (Webb et al., 2005; Simela et al., 2008). Caution is thus advised in terms of any breed improvement programme involving meat goats.

As in the case of cattle, a number of other alternatives are available to improve production and product quality in sheep and goats including the use of the recently discovered callipage gene. There is also a significant variation in sheep and goat genotypes that can be exploited by careful scientific management, while research should include careful analysis of the underlying physiological mechanisms to prevent anatomical, physiological or tissue defects.

\subsection{Muscle defects in rabbits due to selection for accelerated growth}

In rabbits the effects of selection for growth rate is more complex since slaughter weights are fixed (Pascual and Pla, 2007). The consequence is a decrease in maturity at slaughter with concomitant effects on carcass composition, meat colour and the acceptability of the meat. No physiological defects have been reported yet.

\section{Conclusions}

This review suggests that selection for growth and efficiency has reached the physiological limits of animals to cope with the collective demands of maintenance, accelerated growth and development, adaptation, reproduction and in many instances adverse effects are also evident in terms of product quality. Selection for growth has altered the rate and extent of the underlying physiological processes governing growth and development in livestock. Although the emphasis on increased production efficiency remains important in animal agriculture, the physiological limits of animals, the costs associated with new genetic technologies and consumer resistance to modern animal technologies probably limit further progress in terms of improvements in growth and efficiency of livestock and poultry. The current challenge is to make the best use of the available genetic resources and acceptable technologies to the benefit of the livestock industry and consumers alike. Biological and environmental sustainability are also becoming more important, while consumer safety and satisfaction are no longer negotiable.

The livestock industry will have to take note of these important developments in order to meet future consumer demands for safe and healthy food from environmentally acceptable production systems. Although more progress is expected in terms of the efficiency of animal production and quality of animal products, by using quantitative selection programmes in combination with modern tools like genomics, it is essential to understand the underlying physiological processes as well as the genomic-environmental interactions in order to prevent undesirable traits or compromise animal product quality.

\section{References}

Andersson, L., Georges, M., 2004. Domestic-animal genomics: deciphering the genetics of complex traits. Nature Genet. 5, 202-212.

Barbut, S., Sosnicki, A.A., Lonergan, S.M., Knapp, T., Ciobanu, D.C., Gatcliffe, L.J., Huff-Lonergan, E., Wilson, E.W., 2008. Progress in reducing the pale soft and exudate (PSE) problem in pork and poultry meat. Meat Sci. 79, 46-63.

Blasco, A., 2008. The role of genetic engineering in livestock production. Livest. Sci. 113, 191-201.

Bonneau, M., Laarveld, B., 1999. Biotechnology in animal nutrition, physiology and health. Livest. Prod. Sci. 59, 223-241.

Calkins, C.R., Seideman, S.C., Crouse, J.D., 2000. Relationship between rate of growth, catheptic enzymes and meat palatability in young bulls. J. Anim. Sci. 64, 1448-1457.

Cavitt, L.C., Hargis, B.M., Owens, C.M., 2004. The use of halothane and succinylcholine to identify broilers prone to developing pale, soft, exudate meat. Poult. Sci. 83 (8), 1440-1444.

Childe, G., 1936. Man Makes Himself. Oxford University Press.

Eckel, H., Roth, U., Döhler, H., Schultheis, U., 2008. Assessment and reduction of heavy metal input into agro-ecosystems. In: Schlegel, P., Durosoy, S., Jongbloed, A.W. (Eds.), Trace Elements in Animal Production Systems. Wageningen Acaemic Publishers, pp. 33-43.

Fishell, V.K., Aberle, E.D., Judge, M.D., Perry, T.W., 1987. Palatability and muscle properties of beef as influenced by preslaughter growth rate.J. Anim. Sci. 61, $151-157$

Fujii, J., Otsu, K., Zorzato, F., De Leon, F., Khanna, V.K., Weiler, J.E., O'Brien, P.J., MacLennan, D.H., 1991. Identification of a mutation in porcine ryanodine receptor associated with malignant hyperthermia. Science $253,448-451$.

Gao, Y., Zhang, R., Hu, X., Li, N., 2007. Application of genomic technologies to the improvement of meat quality of farm animals. Meat Sci. 77, 36-45.

Grandin, T., 1998. Reducing handling stress improves both productivity and welfare. Prof. Anim. Sci. 4 (1), 1-10.

Green, R.M., Qureshi, M.A., Long, J.A., Burfening, P.J., Hamernik, D.L., 2007. Identifying the future needs for long-term USDA efforts in agricultural animal genomics. Int. J. Biol. Sci. 3, 185-191.

Guàrdia, M.D., Estany, J., Balasch, S., Oliver, M.A., Gispert, M., Diestre, A., 2005. Risk assessment of DFD meat due to pre-slaughter conditions in pigs. Meat Sci. 70, 709-716.

Gupta, A., 2004. Origin of agriculture and domestication of plants and animals linked to early Holocene climate amelioration. Curr. Sci. 87 (1).

Harris, D.L., 1970. Breeding for efficiency in livestock production: defining the economic objectives. J. Anim. Sci. 30, 860-865.

Hassanzadeh, M., Buyse, M., Decuypere, E., 2008. Further evidence for the involvement of anatomical parameters of the cardiopulmonary system in the development of ascites syndrome in broiler chickens. Acta Vet. Hung. 56 (1), 71-80.

Le Bihan-Duval, E., Debut, M., Berri, C.M., Sellier, N., Santé-Lhoutellier, V., Jégo, Y., Beaumont, C., 2008. Chicken meat quality: genetic variability and relationship with growth and muscle characteristics. BMC Genet. 9, 53.

Luger, D., Shinder, D., Wolfenson, D., Yahav, S., 2003. Erythropoiesis regulation during the development of ascites syndrome in broiler chickens: a possible role of corticosterone. J. Anim. Sci. 81, 784-790.

Maga, E.A., Sargent, R.G., Zeng, H., Pati, S., Zarling, D.A., Oppenheim, S.M., Collette, N.M., Moyer, A.L., Conrad-Brink, J.S., Rowe, J.D., BonDurant, R.H., Anderson, G.B., Murray, J.D., 2003. Increased efficiency of transgenic livestock production. Transgenic Res. 12 (4), 485-496.

McCurdy, R.D., Barbut, S., Quinton, M., 1996. Seasonal effects on pale soft excudative (PSE) occurrence in young turkey breast meat. Food Res. Int. 29, 363-366.

Milan, D., Jeon, J.T., Looft, C., Amarger, V., Robic, A., Thelander, M., Rogel-Gillard, C., Paul, S., Iannuccelli, N., Rask, L., Ronne, H., Lundström, K., Reinsch, N., Gellin, J., Kalm, E., Le Roy, P., Chardon, P., Andersson, L., 2000. A mutation in PRKAG3 associated with excess glycogen content in pig skeletal muscle. Science 288, 1248-1251.

Newton, K.G., Gill, C.O., 1977. Storage quality of dark, firm and dry meat. Appl. Environ. Microbiol. 36 (2), 375-376.

Pascual, M., Pla, M., 2007. Changes in carcass composition and meat quality when selecting rabbits for growth rate. Meat Sci. 77, 474-481.

Pavlidis, H.O., Balog, J.M., Stamps, L.K., Hughes Jr, J.D., Huff, W.E., Anthony, N.B., 2007. Divergent selection for ascites incidence in chickens. Poult. Sci. 86, 2517-2529.

Perry, D., Thompson, J.M., 2005. The effect of growth rate during backgrounding and finishing on meat quality traits in beef cattle. Meat Sci. 69, 691-702. 
Pitchford, W.S., 2004. Genetic improvement of feed efficiency of beef cattle: what lessons can be learnt from other species? Aust. J. Exp. Agric. 44 (5), 371-382.

Pursel, V.G., Pinkert, C.A., Miller, K.F., Bolt, D.J., Campbell, R.G., Palmiter, R.D., Brinster, R.L., Hammer, R.E., 1989. Genetic engineering of livestock. Science 244, 1281-1288.

Rosenvold, K., Andersen, H.J., 2003. Factors of significance for porkquality - a review. Meat Sci. 64 (3), 219-237.

Sang, H., 2003. Genetically modified livestock and poultry and their potential effects on human health and nutrition. Trends Food Sci. Technol. 14, 253-263.

Sapkota, A.R., Lefferts, L.Y., McKenzie, S., Walker, P., 2007. What do we feed to food producing animals? A review of animal feed ingredients and their potential impacts on human health. Environ. Health Perspect. 115 (5) 663-670.

Scheele, C.W., Van der Klis, J.D., Kwakernaak, C., Buys, N., Decuypere, E., 2003 Heamatological characteristics predicting susceptability for ascites, 1. High carbon dioxide tensions in juvenile chickens. Br. Poult. Sci. 44 (3), 476-483.

Scheffler, T.L., Gerrard, D.E., 2007. Mechanisms controlling pork quality development: the biochemistry controlling post-mortem energy metabolism. Meat Sci. 77, 7-16.

Short, R.E., MacNeil, M.D., Grosz, M.D., Gerrard, D.E., Grings, E.E., 2002. Pleiotropic effects in Hereford, Limousin and Piedmontese F-2 crossbred calves of genes controlling muscularity including the Piedmontese myostatin allele. J. Anim. Sci. 80, 1-11.

Sillence, M.N., 2004. Technologies for the control of fat and lean deposition in livestock. Vet. J. 167, 242-257.

Simela, L., Webb, E.C., Bosman, M.J.C., 2008. Acceptability of chevon from kids, yearling goats and mature does of indigenous South African goats: a case study. S. Afr. J. Anim. Sci. 38 (3), 247-259.

Steinfeld, H., 2004. The livestock revolution - a global veterinary mission. Vet. Parasitol. 125, 19-41.

Swatland, H.J., 1984. Structure and Development of Meat Animals. Prentice Hall, Inc., Englewood Cliffs, New Jersey.

Swatland, H.J., 2008. How pH causes paleness or darkness in chicken breast meat. Meat Sci. 80, 396-400.

Taylor, G., Swanepoel, F.J.C., Webb, E.C., Stroebel, A., 2008. The effect of nutrition on testicular traits of tropically adapted yearling beef bulls. Aust. J. Exp. Agric. 48, 950-953.
Van den Maagdenberg, K., Stickens, A., Lefaucheur, L., Buys, N., De Smet, S, 2008. The effects of mutations in the insulin-like growth factor-II and ryanodine receptor- 1 genes on biochemical and histochemical muscle fibre characteristics in pigs. Meat Sci. 79, 757-766.

Van Laere, A.S., Nguyen, M., Braunschweig, M., Nezer, C., Collette, C., Moreau, L., Archibald, A.L., Haley, C.S., Buys, N., Tally, M., Andersson, G., Georges, M., Andersson, L., 2003. A regulatory mutation in IGF2 causes a major QTL effect on muscle growth in the pig. Nature 425, 832-836.

Viljoen, H.F., De Kock, H.L., Webb, E.C., 2002. Consumer acceptability of dark, firm and dry (DFD) and normal pH beef steaks. Meat Sci. 61, 181-185.

Wang, L., Brem, T.M., Zarosley, J., Booren, A.M., Strasburg, G.M., 1999. Skeletal muscle calcium channel ryanodine binding activity in genetically unimproved and commercial turkey populations. Poult. Sci. 78, 792-797.

Webb, E.C., 2006. Physiological limits to growth manipulation and the related effects on meat quality. SA-Anim. Sci. 7, 16-21.

Webb, E.C., Casey, N.H., 2005. Achievements of research in the field of growth and development. Animal Production and Animal Science Worldwide, World Association for Animal Production (WAAP) Book of the Year 2005, a Review on Developments and Research in Livestock Systems. Wageningen Academic Publishers, The Netherlands.

Webb, E.C., Mamabolo, M.J., 2004. Production and reproduction characteristics of South African indigenous goats in communal farming systems. S. Afr. J. Anim. Sci. 24 (Suppl.1), 236-239.

Webb, E.C., De Smet, S., Van Nevel, C., Martens, B., Demeyer, D.I., 1998. Effect of anatomical location on the composition of fatty acids in double-muscled Belgian Blue cows. Meat Sci. 50 (1), 45-53.

Webb, E.C., Casey, N.H., Simela, L., 2005. Goat meat quality. Small Rumin. Res. 60, 153-166.

Webb, E.C., Phiri, L.M., Pieterse, E., 2006. Gonadal development of commercial pig genotypes in South Africa. S. Afr. J. Anim. Sci. 36 (5), 26-29.

Whittemore, C., 1993. The Science and Practice of Pig Production. Longman Scientific and Technical.

Yao, L., Dang, Z., 2006. Major chemical components of poultry and livestock manures under intensive breeding. Ying Yong Sheng Tai Xue Bao 17 (10), 1989-1992. 